\title{
Nanocarriers for transdermal drug delivery
}

This article was published in the following Dove Press journal:

Research and Reports in Transdermal Drug Delivery

12 November 2012

Number of times this article has been viewed

\author{
José Juan Escobar-Chávez' \\ Roberto Díaz-Torres ${ }^{2}$ \\ Isabel Marlen Rodríguez- \\ $\mathrm{Cruz}^{3}$ \\ Clara Luisa Domínguez- \\ Delgado ${ }^{4}$ \\ Rafael Sampere Morales ${ }^{5}$ \\ Enrique Ángeles-Anguiano ${ }^{6}$ \\ Luz María Melgoza- \\ Contreras $^{7}$ \\ 'Sistemas Transdérmicos y Materiales \\ Nanoestructurados, ${ }^{2}$ Toxicología \\ y Genética, Universidad Nacional \\ Autónoma de México, Cuautitlán \\ Izcalli, México; ${ }^{3}$ Unidad de Enseñanza \\ e Investigación, Hospital Regional \\ de Alta Especialidad de Zumpango, \\ Zumpango, México; ${ }^{4}$ Departamento \\ de Ingeniería y Tecnología, \\ ${ }^{5}$ Departamento de Ciencias \\ Químicas, 'Laboratorio de Química \\ Medicinal, Universidad Nacional \\ Autónoma de México, Cuautitlán \\ Izcalli, México; ${ }^{7}$ Departamento de \\ Sistemas Biológicos, Universidad \\ Autónoma Metropolitana-Xochimilco, \\ México City, México
}

Correspondence: José Juan Escobar-

Chávez

Laboratorio 12 - Sistemas Transdérmicos y Materiales Nanoestructurados, Facultad de Estudios Superiores Cuautitlán, Universidad Nacional Autónoma de México, Km 2.5 Carretera Cuautitlán-

Teoloyucan, San Sebastián Xhala,

Cuautitlán Izcalli, Estado de México

547|4, México

Tel +52 5556231999 ext 39442

Email josejuanescobarchavez@gmail.com
Abstract: Transdermal drug delivery offers an attractive alternative to the conventional drug-delivery methods of oral administration and injection. Apart from the convenience and noninvasiveness, the skin also provides a "reservoir" that sustains delivery over a period of days. It offers multiple sites to avoid local irritation and toxicity, yet it can also offer the option of concentrating drugs at local areas to avoid undesirable systemic effects. However, at present, the clinical use of transdermal delivery is limited by the fact that very few drugs can be delivered transdermally at a viable rate. This difficulty is because the stratum corneum of skin acts as an efficient barrier that limits penetration of drugs through the skin, and few noninvasive methods are known to significantly enhance the penetration of this barrier. In order to increase the range of drugs available for transdermal delivery, the use of nanocarriers has emerged as an interesting and valuable alternative for delivering lipophilic and hydrophilic drugs throughout the stratum corneum with the possibility of having a local or systemic effect for the treatment of many different diseases. These nanocarriers (nanoparticles, ethosomes, dendrimers, liposomes, etc) can be made of a lot of different materials, and they are very different in structure and chemical nature. They are too small to be detected by the immune system, and furthermore they can deliver the drug in the target organ using lower drug doses in order to reduce side effects.

Keywords: skin, transdermal drug delivery, transdermal nanocarriers, nanoparticles, dendrimers, liposomes, nanoemulsions, transfersomes

\section{Introduction}

Nanomedicine has become a very relevant topic nowadays. Since the last century, there has been a lot of new research and patents regarding nanomedicine in health sciences. ${ }^{1}$ The main goal of nanomedicine is to diagnose and preserve health without side effects by using noninvasive treatments. The manipulation that nanomedicine provides to the drugs and other materials in the nanometer scale $(1-500 \mathrm{~nm}) \mathrm{can}$ change the basic properties and bioactivity of materials. The solubility, increment in surface area, control release, and site-targeted delivery are some characteristics that nanotechnology can manipulate in drug-delivery systems. ${ }^{2}$

Nanotechnology applied to health sciences contains new devices used in surgery, new chips for better diagnostics, new materials for substituting body structures, and some structures capable of carrying drugs through the body for the treatment of a lot of diseases. These structures can be made of a lot of different materials, and they are very different in structure and chemical nature. All these nanostructures are called nanocarriers, and they can be administered into the organisms by topical and transdermal routes. ${ }^{3}$ The idea for using these tiny systems is not new, but the use of submit your manuscript | www.dovepress.com

Dovepress

http://dx.doi.org// 0.2147/RRTD.S3262।
Research and Reports in Transdermal Drug Delivery 2012:I 3-17 3

(C) 2012 Escobar-Chávez et al, publisher and licensee Dove Medical Press Ltd. This is an Open Access article which permits unrestricted noncommercial use, provided the original work is properly cited. 
nanocarriers in pharmaceutical products is not frequent, since the technology is expensive for certain types of nanoparticles and because nanocarriers need to be evaluated to demonstrate they do not have toxic effects. Nowadays, the controversy of biological effects due to nanostructures is an open discussion: on one hand, nanotechnologists continue making new and more sophisticated nanocarriers, and on the other hand, toxicologists continue evaluating possible damaging effects. ${ }^{3,4}$ New nanocarriers will be created, and all scientists working in nanomedicine hope for this field to provide the cure for diseases that at this moment are difficult to deal with. ${ }^{4}$

Over time, the skin has become an important route for drug delivery when topical, regional, or systemic effects are desired. ${ }^{5}$ Nevertheless, skin constitutes an excellent barrier and presents difficulties for the transdermal delivery of therapeutic agents, since few drugs possess the characteristics required to permeate across the stratum corneum (SC) in sufficient quantities to reach a therapeutic concentration in the blood. In order to enhance drug transdermal absorption, different methodologies have been investigated, developed, and patented. ${ }^{6,7}$ Improvement in physical permeationenhancement technologies has led to renewed interest in transdermal drug delivery. Some of these novel advanced transdermal permeation-enhancement technologies include iontophoresis, electroporation, ultrasound, microneedles to open up the skin, and more recently the use of transdermal nanocarriers. ${ }^{4,8-11}$

A number of excellent reviews that have been published contain detailed discussions concerning many aspects of transdermal nanocarriers. ${ }^{12-18}$ The present article shows an updated overview of the use of submicron particles and other nanostructures in the pharmaceutical field, specifically in the area of topical and transdermal drugs. This focus is justified due to the magnitude of the experimental data available on the use of these nanocarriers. The development of submicron particles and other nanostructures in the pharmaceutical and cosmetic fields has been emerging in the last few decades for designing best formulations for application through the skin. ${ }^{19-22}$

\section{The skin}

The skin is the largest organ of the body, ${ }^{23-25}$ accounting for more than $10 \%$ of body mass; it enables the body to interact more intimately with its environment. Essentially, the skin consists of four layers (Figure 1):

1. The SC, which is the outer layer of the skin. It forms the rate-controlling barrier for diffusion for almost

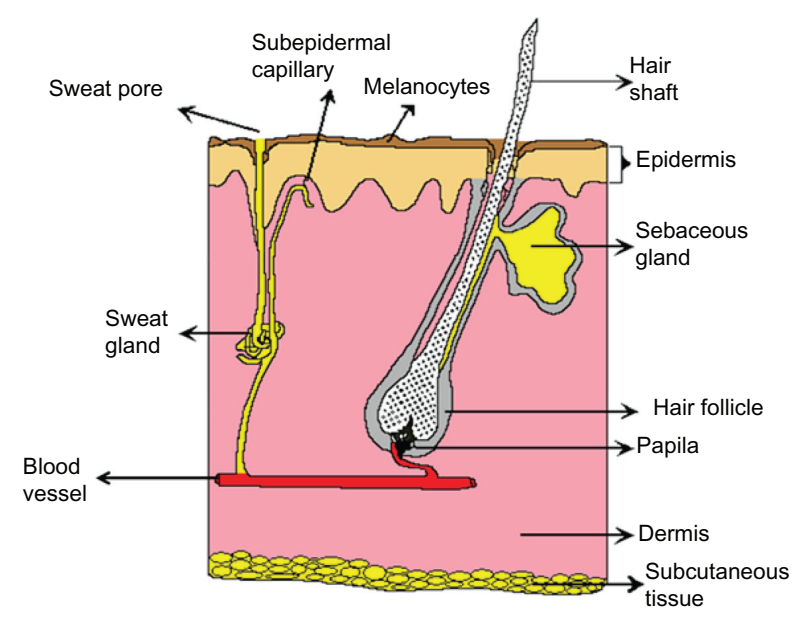

Figure I Schematic representation of skin layers.

all compounds. It is composed of dead, flattened, keratinrich cells - the corneocytes. These dense cells are surrounded by a complex mixture of intercellular lipids: ceramides, free fatty acids, cholesterol, and cholesterol sulfate. Their most important feature is that they are structured as ordered bilayer arrays. ${ }^{26}$ The predominant diffusional path for a molecule crossing the SC appears to be intercellular. ${ }^{27-29}$

2. Remaining layers of the epidermis (viable epidermis).

3. The dermis.

4. Subcutaneous tissue.

There are also several associated appendages: hair follicles, sweat ducts, glands, and nails, but these occupy only about $0.1 \%$ of the total human skin surface. ${ }^{30,31}$

The hair follicles are distributed across the entire skin surface, with the exception of the soles of the feet, the palms of the hand, and the lips. Each follicle is associated with a sebaceous gland that varies in size from 200 to $2000 \mu \mathrm{m}$ in diameter. The sebum secreted by this gland, consisting of triglycerides, free fatty acids, and waxes, protects and lubricates the skin as well as maintaining a $\mathrm{pH}$ of about 5.5. ${ }^{31}$ The ecrine glands are epidermal structures that are simple, coiled tubes arising from a coiled ball, of approximately $100 \mu \mathrm{m}$ in diameter, located in the lower dermis. It secretes a dilute salt solution with a $\mathrm{pH}$ of about 5 ; this secretion being stimulated by temperature-controlling determinants, such as exercise and high environmental temperature, as well as emotional stress through the autonomic (sympathetic) nervous system. Many things can interfere with the delicate structure of the skin's acid mantle (formed by the sebum and sweat of skin) externally and internally. As we age, our skin becomes more acidic in response to our lifestyle and 
our environment. Everything that comes in contact with our skin (products, smoking, air, water, sun, pollution) contributes to the breaking down of the acid mantle and the skin's ability to protect itself. ${ }^{8,31}$ The acid mantle is a form of protection, but if our $\mathrm{pH}$ level is too alkaline or too acidic, this mantle is disturbed, skin conditions such as dermatitis, eczema, and rosacea may result, and skin drug permeability can change dramatically.

In a general context, the skin's functions may be classified as protective, homeostasis-maintaining, or sensing. ${ }^{30,31}$

Many agents are applied to the skin either deliberately or accidentally, with either beneficial or deleterious outcomes. The main interest in dermal absorption assessment is related to:

1. Local effects in dermatology ${ }^{32}$

2. Transport through the skin, seeking a systemic effect ${ }^{32}$

3. Surface effects ${ }^{33,34}$

4. Targeting of deeper tissues ${ }^{35-38}$

5. Unwanted absorption. ${ }^{39,40}$

\section{Routes of drug penetration through the skin}

The permeation of drugs through the skin includes the diffusion through the intact epidermis through the skin appendages (hair follicles and sweat glands). These skin appendages form shunt pathways through the intact epidermis, occupying only $0.1 \%$ of the total human skin. ${ }^{41}$ It is known that drug permeation through the skin is usually limited by the SC. Two pathways through the intact barrier may be identified (Figure 2).

\section{The intercellular lipid route}

Interlamellar regions in the $\mathrm{SC}$, including linker regions, contain less ordered lipids and more flexible hydrophobic chains. This is the reason for the nonplanar spaces between crystalline lipid lamellae and their adjacent cells' outer membrane. Fluid lipids in skin barrier are crucially important for transepidermal diffusion of the lipidic and amphiphilic molecules, occupying those spaces for the insertion and migration through intercellular lipid layers of such molecules. ${ }^{42,43}$ The hydrophilic molecules diffuse predominantly "laterally" along surfaces of the less abundant water-filled interlamellar spaces or through such volumes; polar molecules can also use the free space between a lamella and a corneocyte outer membrane to the same end. ${ }^{44}$

\section{The transcellular route}

Intracellular macromolecular matrix within the SC abounds in keratin, which does not contribute directly to the skin diffusive barrier but supports mechanical stability and thus intactness of the SC. Transcellular diffusion is practically unimportant for transdermal drug transport. ${ }^{45,46}$ The narrow

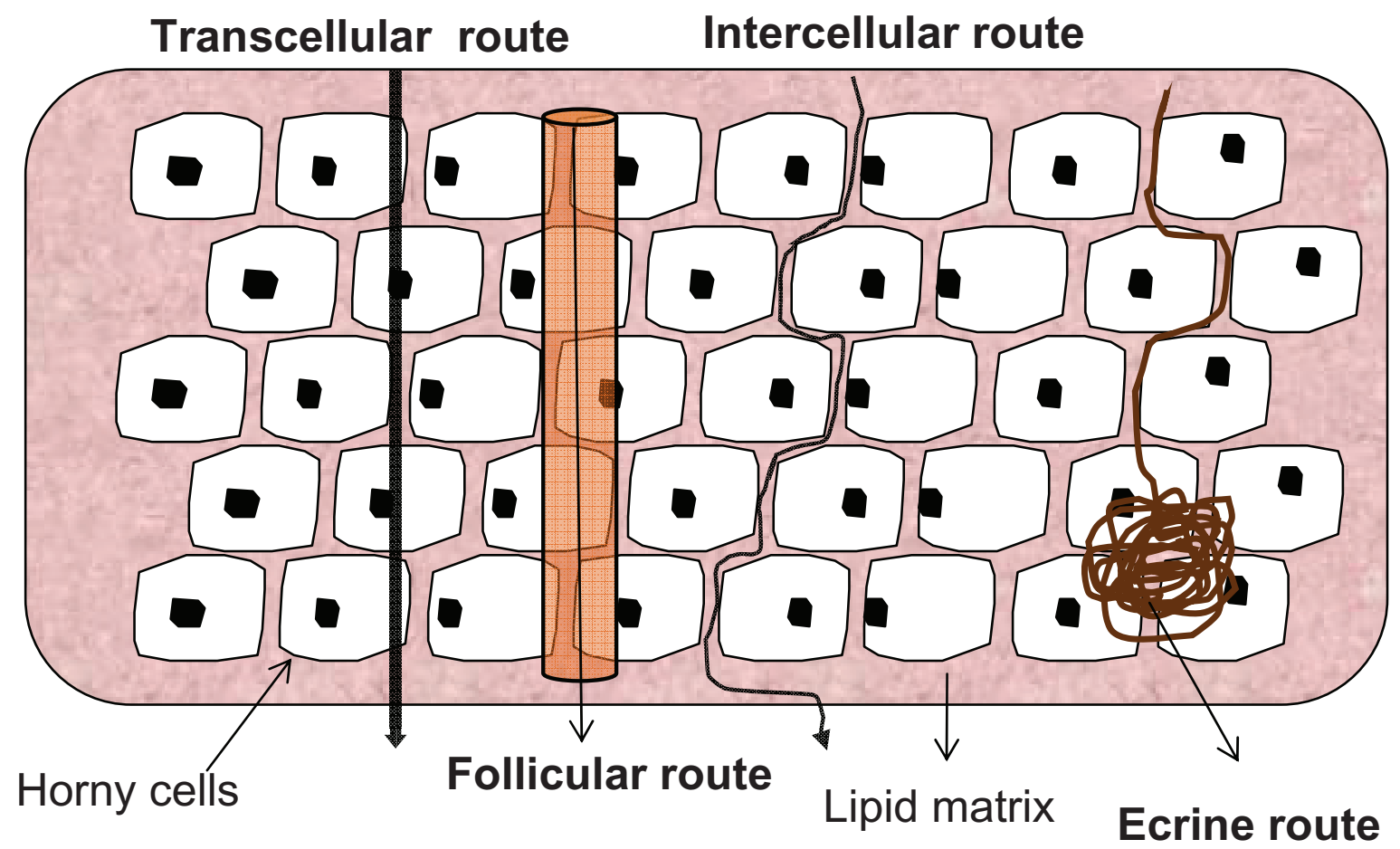

Figure 2 Processes of percutaneous absorption of drugs through the skin. 
aqueous transepidermal pathways have been observed using confocal laser scanning microscopy. Here, regions of poor cellular and intercellular lipid packing coincide with wrinkles on skin surface and are simultaneously the sites of lowest skin resistance to the transport of hydrophilic entities. This lowest-resistance pathway leads between clusters of corneocytes at the locations where such cellular groups show no lateral overlap. ${ }^{47-51}$

The contribution to transdermal drug transport can increase with pathway widening or multiplication, eg, that which is caused by exposing the SC to a strong electrical (electroporation/iontophoresis), mechanical (sonoporation/sonophoresis), or thermal stimulus, or suitable skin penetrants. ${ }^{52}$

Recently, follicular penetration has become a major focus of interest due to the fact that drug targeting to the hair follicle is of great interest in the treatment of skin diseases. However, follicular orifices occupy only $0.1 \%$ of the total skin surface area. For this reason, it was assumed to be a nonimportant route for drug penetration. But a variety of studies have shown that hair follicles could be an interesting option for drug penetration through the skin. ${ }^{53-58}$ Such follicular pathways have also been proposed for topical administration of polystyrene nanoparticles. They were investigated in porcine skin (in vitro) and human skin (in vivo). Surface images revealed that polystyrene nanoparticles accumulated preferentially in the follicular openings. This distribution was increased in a time-dependent manner, and the follicular localization was favored by the smaller particle size. ${ }^{59}$ The study also confirmed similarity in the penetration between both membranes (porcine and human skin). ${ }^{57}$ In other investigations, the influence of microparticle size in skin penetration has been shown by differential stripping. Nanoparticles can act as efficient drug carriers or can be utilized as follicle blockers to stop the penetration of topically applied substances. ${ }^{58,60}$

A number of methods are currently available for quantifying drugs localized within the skin. ${ }^{61}$ There is no direct, noninvasive technique to quantify penetrated drug into follicles, but the tape-stripping technique $e^{23,27,61}$ and cyanoacrylate skin surface biopsy ${ }^{61}$ have been used to remove layers of the SC containing dyes or drugs topically applied. ${ }^{61}$ Of the two techniques, tape stripping has been more successful due to non-invasiveness and selectivity to study penetration of skinapplied substances in the follicular infundibula. .1,27,31,61,62 $^{2}$

\section{Advantages and disadvantages of transdermal drug delivery}

Transdermal drug-delivery systems offer several important advantages over more traditional approaches, in addition to the benefits of avoiding the hepatic first-pass effect. Higher patient compliance and additional advantages and disadvantages ${ }^{63-65}$ that transdermal drug delivery offers is summarized in Table 1.

\section{Transdermal nanocarriers}

The types of nanocarriers that are used today have significantly increased in the last decades. These systems are designed around the two characteristics that are sought in the modern pharmacy: temporal delivery and spatial location.

It is hard to say what is the ideal nanocarrier, because every day new advantages and disadvantages of each are discovered. ${ }^{12-18}$ We can mention as general advantages improvements in drug solubility, permeability, half-life, bioavailability, and stability, among other properties, ${ }^{66}$ and the main disadvantages are low load capacity in many cases and lack of stability of the system per se. ${ }^{67}$

An important point highlighted by Panariti et al ${ }^{68}$ is that physicochemical properties of nanocarrier systems determine the interaction with biological systems and nanocarrier cell internalization. The main physicochemical properties that affect cellular uptake are size, shape, rigidity, and charge in the surface of nanoparticles (see Table 2).

Nanoparticulated systems can be administered into organisms by almost all routes including transdermal, ${ }^{69,70}$ which offers several advantages over other delivery systems, but with its own limitations (see Table 1). The most used and investigated nanocarriers for topical/transdermal drug delivery in the pharmaceutical field, ${ }^{71}$ as a function of the material used to prepare them, are shown in Figure 3, and a

Table I Main advantages and disadvantages of transdermal drug delivery

\begin{tabular}{ll}
\hline $\begin{array}{l}\text { Advantages of transdermal } \\
\text { drug delivery }\end{array}$ & $\begin{array}{l}\text { Disadvantages of } \\
\text { transdermal drug delivery }\end{array}$ \\
\hline Prolonged duration of action & $\begin{array}{l}\text { Possibility of local irritation at } \\
\text { the site of application } \\
\text { Skin irritation or contact } \\
\text { dermatitis due to drug or } \\
\text { exipients } \\
\text { Reduction in the frequency } \\
\text { of dosing }\end{array}$ \\
$\begin{array}{l}\text { More uniform plasma levels } \\
\text { the number of drugs that can } \\
\text { be delivered in this manner }\end{array}$ \\
$\begin{array}{l}\text { Useful for potent drugs } \\
\text { Improvement in bioavailability }\end{array}$ \\
$\begin{array}{l}\text { Reduction of adverse effects } \\
\text { Flexibility of terminating drug } \\
\text { administration by simply removing } \\
\text { the transdermal delivery system } \\
\text { from the skin (patch) }\end{array}$ \\
\hline
\end{tabular}


Table 2 Influence of main physichochemical properties of nanocarrier systems on cell uptake

\begin{tabular}{ll}
\hline Favors the uptake & $\begin{array}{l}\text { Does not favor the uptake } \\
\text { or decreases the uptake }\end{array}$ \\
\hline $\begin{array}{l}\text { Spherical shape } \\
\text { Positive surface charge }\end{array}$ & Large size \\
Small size & Negative surface charge \\
Rigidity & \\
\hline
\end{tabular}

schematic representation of some nanocarriers is shown in Figure 4. This manuscript includes the most important carriers for transdermal drug delivery. Liposomes, transfersomes, ethosomes, niosomes, dendrimers, nanoparticles, and nanoemulsions are currently the main subjects when searching for transdermal drug delivery.

\section{Liposomes}

Liposomes are lipid bilayer systems that can carry hydrophilic drugs inside the core and lipophilic drugs between the bilayer. They were created by Alec Bangham. He realized that phospholipids in aqueous systems can form hollow, bilayered structures. ${ }^{4}$ Liposomes have become one of the pharmaceutical nanocarriers of choice for many purposes. In recent years, many liposome-based drugs and biomedical products have been approved for use as medicines. ${ }^{72}$

In transdermal delivery, liposomes have been used widely. They are systems made of cholesterol and phospholipids.
Their physicochemical properties depend on the materials used for their fabrication and the process performed. Liposomes are one of the best alternatives for drug delivery because they are nontoxic and remain inside the bloodstream for a long time. ${ }^{73}$

Many factors can affect transdermal penetration of liposomes, eg, particle size and formulation, as well as the presence of penetration enhancers and the physical state of the SC, but there are other important variables like lamellarity, lipid composition, charge on the liposomal surface, mode of application, and total lipid concentrations. Liposomes have been used successfully to transport drugs across the skin. ${ }^{74}$

The liposome lipid content makes the interaction of these entities with biological membranes easier. There has been research on the interaction between lipids present in the SC and liposome lipid bilayer, changing the structure of the upper skin. This interaction favors the penetration through the SC of lipophilic drugs. ${ }^{75}$

\section{Transfersomes}

Some liposomes may have a deformable structure and pass through the SC or may accumulate in the channel-like regions in the SC, depending upon their composition. The driving force is nothing more than osmotic pressure; these liposomes are called transfersomes or transformable liposomes. ${ }^{76}$

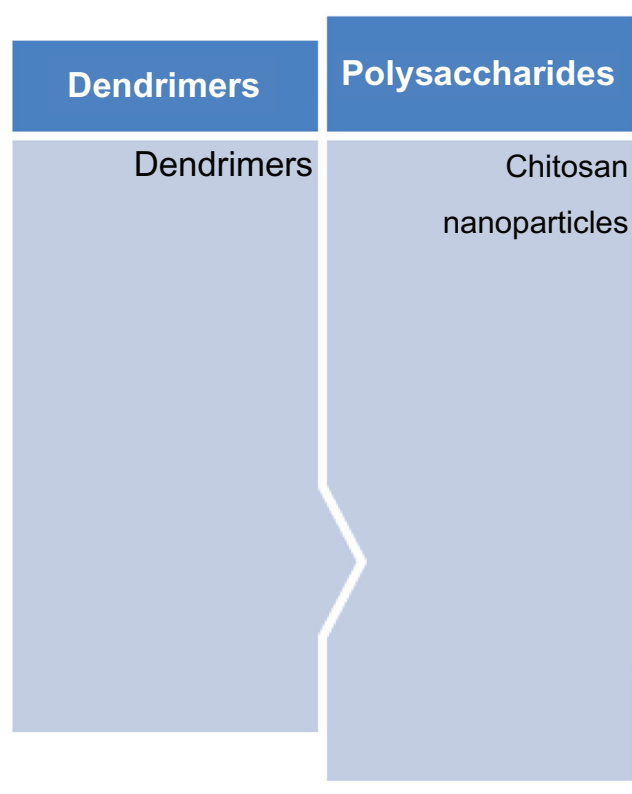

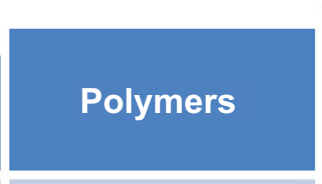

Polyalkylcyanoac rylates nanoparticles

Polylactic acid nanoparticles

Polylactic-coglycolic acid nanoparticles

Polycaprolactone nanoparticles

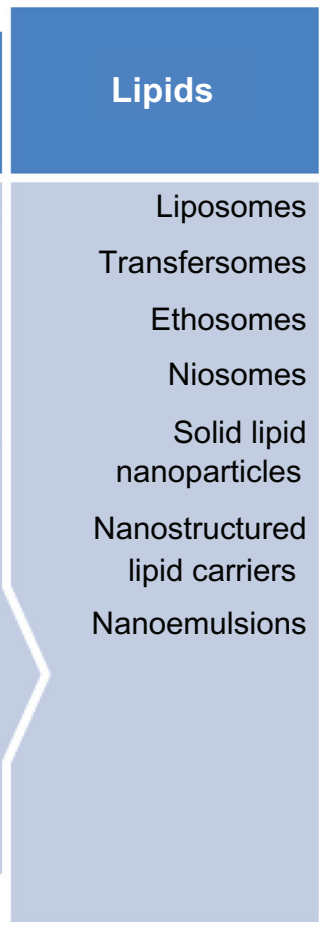

Figure 3 Carriers commonly used in transdermal drug delivery as a function of material used to prepare them. 

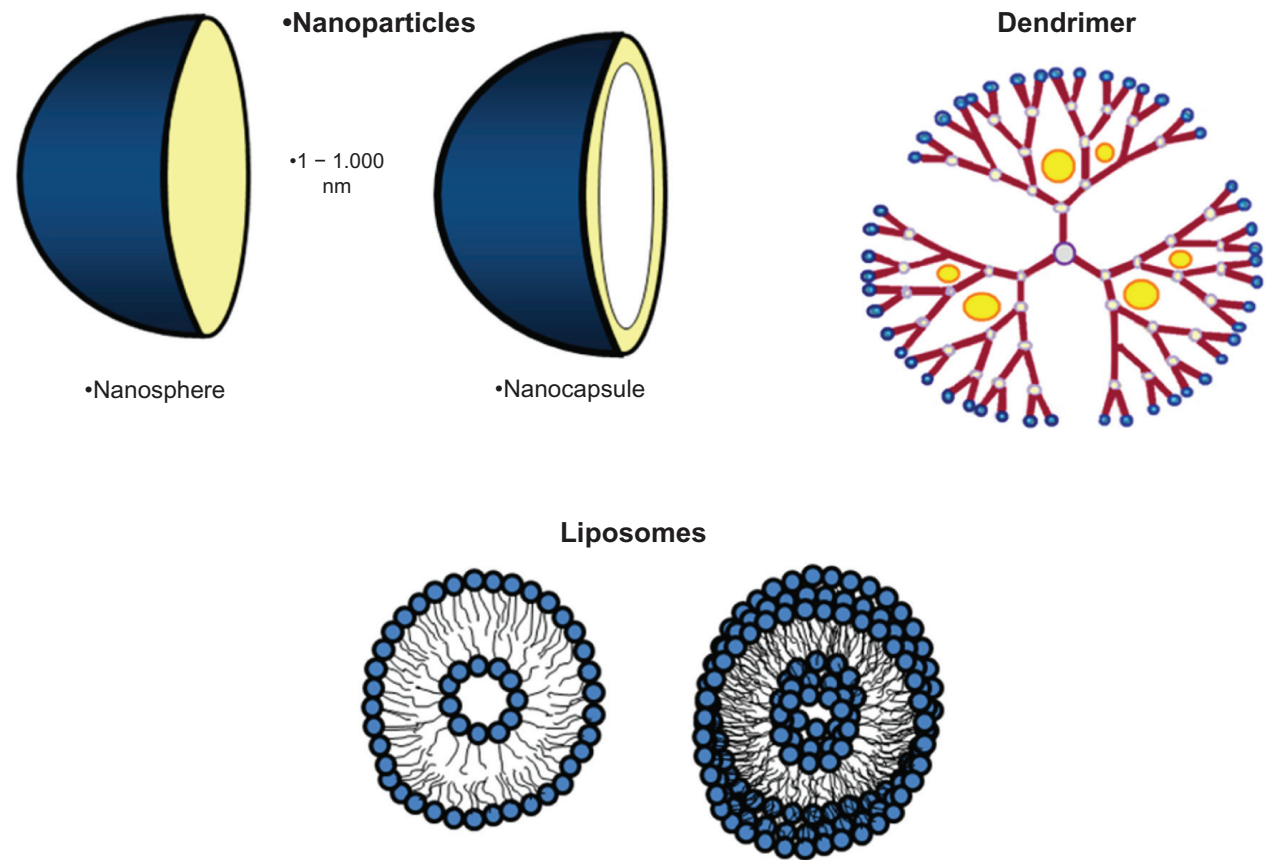

Figure 4 Schematic representation of some nanocarrier systems used for transdermal drug delivery.

The need to reach the narrow tubes that make up the skin (hair follicles and intercellular spaces between lipids), to deliver drugs, led to the invention of transfersomes. The original idea to use liposomes as drug delivery systems was very smart, as they are made of lipids similar to biological membranes, but they have rigid structure. The incorporation of elements in the lipid bilayer to make it flexible has made these carriers successful. Traditional transformable liposomes are made using surfactants in the lipid bilayer. In transdermal drug delivery, the paracellular and intercellular pathways are very important but appendage routes have been of increasing interest lately. ${ }^{77}$ The use of flexible liposomes (transformable liposomes) is an invaluable strategy to reach the objective of drug delivery via the transdermal route. The use of these kinds of nanocarriers seems to be more effective than liposomes, and their flexibility allows the possibility of using them as transdermal vaccine vectors.

\section{Ethosomes}

The idea of making another kind of flexible liposome has been the goal of a lot of scientists. To that end, the ethosomes, which contain alcohol in the lipid bilayer to make them more flexible and be able to be deformed when pressure is applied, ${ }^{78}$ were created.

These carriers allow drugs to reach deeper skin layers and systemic circulation. Ethosomes are easy to prepare, and they are considered safe and efficient. For these reasons, they could have wide future applications. ${ }^{79}$ Their main characteristics are softness and malleability, and they are considered good drug-delivery systems. Ethosomes are able to contain and deliver a lot of molecules because they can transport highly lipophilic drugs, eg, testosterone, minoxidil, and cationic molecules such as propranolol and trihexyphenidil. ${ }^{80}$

Ethosomes can carry and deliver a lot of drugs, and in the future these systems offer a huge opportunity to make better therapies, besides which they can transport molecules through the skin and biological membranes. Examples of the application of these nanocarriers in transdermal delivery are widely described in the next section.

\section{Niosomes}

Niosomes are made of lipids (like cholesterol) and nonionic surfactants, which are biodegradable and minimally toxic. Niosomes were created with the same goal as transfersomes and ethosomes: to make liposomes less rigid and let these bilayer systems go where liposomes cannot go ${ }^{81}$ In addition, the incorporation of nonionic surfactants let the liposomes be more stable. The niosomes were originally used in the cosmetics industry, and the versatility of these systems has allowed their use to spread to other areas. For example, in pharmaceutical products, they are formulated for drug delivery. They are used for many routes of administration: oral, parenteral, ocular, and vaginal, including transdermal. ${ }^{82}$ The application of niosomes in transdermal drug delivery has been very important, because they can carry anti-aging 
agents and antifungal molecules, among other drugs. A more comprehensive review is in the applications section.

\section{Dendrimers}

Dendrimers are nonpeptidic fractal 3-D structures made of numerous small molecules. The term "dendrimer" is Greek: "dendra" means tree and "meros" means part. This name was coined in the late 1970 s by a research group formed by Vögtle, Denkewalter, Tomalia, and Newkome. The structure of these molecules results in relatively uniform shapes, sizes, and molecular weights. They are a very good alternative for drug-delivery systems; dendrimers can be used in antiviral and anticancer pharmaceutical therapies, including vaccines. ${ }^{83}$

The first material used and still most commonly used for dendrimer fabrication is poly(amidoamine), which was initially synthesized by Dow Laboratories between 1979 and 1985. In the context of controlled chemical delivery, dendrimers have been explored for drug delivery, gene therapy, and delivery of contrast agents. ${ }^{84}$

The use of dendrimers to encapsulate hydrophobic and labile molecules has been a successful road. The permeability of dendrimers through the skin depends on physicochemical characteristics like generation size, molecular weight, surface charge, composition, and concentration. ${ }^{85}$ Dendrimers as transdermal drug-delivery systems are relatively new, but there are numerous recent papers. ${ }^{2,4,8,83}$ These nanocarriers have been used to transport photosensitizers for photochemical therapy and antifungal molecules.

\section{Nanoparticles}

The main goal of delivery systems is to reach the organ of interest and often to go through it. The use of carriers like those previously mentioned in this text, in addition to the theme of this topic (nanoparticles), contributes to accomplishing this objective. Recently, scientists have developed lots of nanocarriers for helping to improve drug transport into the skin and through biological membranes.

As mentioned in previous paragraphs, the skin is an important route to go into the body, and with its larger contact area it can be very useful to administer drugs locally and systemically. ${ }^{86}$ Nanotechnology in the pharmaceutical sciences opens a new avenue of therapies for the treatment of many diseases and represents hope that people may be helped to have a better life. Nowadays, it is possible to encapsulate a variety of molecules into nanoparticles like drugs, proteins, peptides, DNA, etc. Moreover, nanomaterial, such as gold nanoparticles, has been used for transdermal delivery; for example, to encapsulate protein drugs to enable percutaneous delivery, the interaction between the gold nanoparticles and the skin barrier leads to an increase of skin permeability and effectively prompts percutaneous absorption of the coadministered proteins. ${ }^{87}$ The main advantage of codelivery is that it does not require the loading of drugs into the nanoparticulate system. Therefore, compromise in activity can be minimized for both protein drugs and nanoparticles because of the exclusion of complicated drug-loading processes. This highlights a new strategy for percutaneous protein delivery, with obvious advantages in terms of simplicity and cost-effectiveness. Also, a combined multiphotonpixel analysis method was developed for semiquantitation of gold nanoparticle penetration into different skin layers. ${ }^{88}$ Gold nanoparticles are also commonly used in cosmetic products such as facial gold masks. Protein nanofiber gold nanoparticle creams and gold nanoparticle masks have been claimed to enhance the firmness of skin and to have a rejuvenating action. ${ }^{89}$ Silver nanoparticles are similar to solid-drug nanoparticles in that the active agent appears to be the breakdown product of the particle. Silver nanoparticles exhibit minimal penetration into skin and are consequently considered safe. Studies of long-term occupational exposure to silver ions and silver nanoparticles have concluded that they are relatively nontoxic. ${ }^{90}$ In many cases, lots of molecules have been difficult to administer using conventional therapeutic systems; in addition, the doses that need to be given to patients using conventional delivery methods reach toxic levels, or cause a lot of side effects.

Nanoparticles in a liquid form colloids due to their size and can be classified as nanospheres or nanocapsules. Nanospheres are solid-core structures, and nanocapsules are hollow-core structures. ${ }^{91}$ They can also be classified depending on the material from which they were made, eg, if they are made of lipids, polymers, polysaccharides, or proteins.

Nanoparticle-preparation techniques are based on their physicochemical properties. They are made by emulsification-diffusion by solvent displacement, emulsification-polymerization, in situ polymerization, gelation, nanoprecipitation, solvent evaporation/extraction, inverse salting out, dispersion polymerization, and other techniques derived from these. ${ }^{2,4}$

Two of the main options for transdermal delivery are the solid-lipid nanoparticles and nanostructure lipid carriers. Aside from polysaccharide nanoparticles, polymeric nanoparticles are very good options for transdermal delivery because they can be tailor-made in different sizes and it is possible to modify their surface polarity in order to improve 
skin penetration..$^{92}$ From the upper skin, lipid nanoparticles can reach deeper skin regions because they exhibit mechanical flexion. Nanoparticles can even travel from the skin to lymph nodes, representing a promising tool for immunomodulation. ${ }^{93}$

\section{Nanoemulsions}

Nanoemulsions are isotropic dispersed systems of two nonmiscible liquids, normally consisting of an oily system dispersed in an aqueous system, or an aqueous system dispersed in an oily system but forming droplets or other oily phases of nanometric sizes. They are thermodynamically nonstable systems, in contrast to microemulsions, because nanoemulsions need high energy to produce them. They are susceptible to Oswald ripening, and as a consequence susceptible to creaming, flocculation, and other physical instability problems associated with emulsions. Despite this, they can be stable (methastable) for long periods due to their extremely small size and the use of adequate surfactants. Hydrophobic and hydrophilic drugs can be formulated in nanoemulsions because it is possible to make water/oil or oil/water nanoemulsions. ${ }^{2,4,94}$ They are nontoxic and nonirritant systems, and they can be used for skin or mucous membranes and parenteral and nonparenteral administration in general, and they have been utilized in the cosmetic field. Nanoemulsions can be prepared by three methods mainly: high-pressure homogenization, microfluidization, and phase-inversion temperature. Transdermal delivery using nanoemulsions has decreased due to the stability problems inherent to this dosage form. Some examples of drugs using nanoemulsions for transdermal drug delivery are gamma tocopherol, caffeine, plasmid DNA, aspirin, methyl salicylate, insulin and nimesulide. 2,4,95

In general, the advantages and limitations of using nanocarriers for transdermal drug delivery are their tiny size, their high surface energy, their composition, their architecture, and their attached molecules. Table 3 shows advantages and disadvantages of these carrier systems.

\section{Applications of nanocarrier systems for transdermal drug delivery}

As has been mentioned before, the search for new strategies able to enhance the topical and transdermal penetration of drugs has become essential. ${ }^{2-4,8-11}$ Different carrier systems have been proposed in an attempt to favor the transport of drugs through the skin, enabling drug retention and in some cases allowing a controlled release. Table 4 summarizes the applications of nanocarrier systems for transdermal drug delivery. Skin penetration is essential to a number of current concerns, eg, contamination by microorganisms and chemicals, drug delivery to skin (dermatological treatments) and through skin (transdermal treatments), and skin care and protection (cosmetics). ${ }^{58,60,76,82,84,85}$

Liposomes have become one of the pharmaceutical nanocarriers of choice for many applications. Currently, many liposome-based drugs and biomedical products have been approved for use in clinic. They were used to study membrane processes and membrane-bound proteins. Liposomes were also proposed as drug carriers that reduce toxicity and increase efficacy. The nature of liposomes makes them one of the best alternatives for drug delivery because they are nontoxic and remain inside the bloodstream for a long time. They are being successfully used in cancer therapy and in skin melanoma. ${ }^{96-99}$ However, to date many liquid-type nanocosmetic carriers, such as liposomes, are structurally unstable. Specifically, when passing through the skin, they adhere to the inside walls of the skin cells, causing the collapse of phospholipid-association bodies and the leak of their encapsulated ingredients. As a result, their ability to transport active ingredients to deep skin is not likely good. For this reason, the use of flexible liposomes (transformable liposomes or transfersomes) has emerged as an invaluable strategy to reach the objective of drug delivery via the transdermal route. Table 4 shows some examples of drugs delivered through the skin by using liposomes and transfersomes.

The application of transformable liposomes, which are prepared using alcohol (ethosomes) in the lipid bilayer of SC, able to deform and penetrate throughout the skin when pressure is applied, has been increased. For example, tacrolimus-loaded ethosomes may be useful as a therapeutic agent for atopic dermatitis. ${ }^{100}$ Skin permeation of ethosomal formulations assessed by confocal microscopy revealed enhanced permeation of Rhodamine 123-loaded formulation in comparison to the hydroalcoholic solution. Another ethosomal formulation has proved to be a potentially useful vehicle for transdermal delivery of ketoprofen. ${ }^{101}$ Furthermore, an ethosomal carrier (phosphatidylethanolamine) is an optional treatment for psoriasis that provides long-term therapeutic effects, is nontoxic, and has better compliance with patients. Application of ethosomal carriers with 5-aminolevulinic acid (ALA) in hyperproliferative murine skin can improve the penetration of ALA and the formation of protoporphyrin IX and significantly reduce tumor necrosis factor in this disordered skin compared to an ALA aqueous solution. ${ }^{102}$

Ethosomes were used efficiently to enhance the anti-inflammatory activity of ammonium glycyrrhizinate compared to the ethanolic or aqueous solutions of this drug. ${ }^{103}$ 
Table 3 Advantages and disadvantages of nanocarrier systems

\begin{tabular}{|c|c|c|}
\hline Nanocarrier & Advantages & Disadvantages \\
\hline Nanoparticles & $\begin{array}{l}\text { They can be made of a lot of biodegradable materials. } \\
\text { There are many ways to prepare them. } \\
\text { They can include antibodies in their surface to reach target } \\
\text { organs. } \\
\text { Both hydrophilic and hydrophobic drugs can be loaded in a } \\
\text { nanoparticle. } \\
\text { They are able to avoid the immune system due to their size. }\end{array}$ & $\begin{array}{l}\text { Not enough toxicological assessment has been done. } \\
\text { It is difficult to develop an analytical method for drug } \\
\text { delivery. } \\
\text { Some processes are difficult to scale up. } \\
\text { Sometimes, the size they reach is not enough to avoid } \\
\text { the immune system. }\end{array}$ \\
\hline Nanoemulsions & $\begin{array}{l}\text { They can be formulated as foams, liquids, creams, and sprays. } \\
\text { They are nontoxic and nonirritant. } \\
\text { Easily applied to skin and mucous membranes. }\end{array}$ & $\begin{array}{l}\text { They are susceptible to Oswald ripening. } \\
\text { Surface charge has a marked effect on stability. } \\
\text { Variable kinetics of distribution processes and } \\
\text { clearance. }\end{array}$ \\
\hline Liposomes & $\begin{array}{l}\text { Control release based on natural lipids. } \\
\text { High biocompatibility. } \\
\text { Simple manufacture. } \\
\text { Protein carriers increase their stability. } \\
\text { High drug loads. }\end{array}$ & $\begin{array}{l}\text { When high-pressure homogenization is used, decreased } \\
\text { stability of high-weight molecules. } \\
\text { Lipid crystallization leads to a lot of polymorphic } \\
\text { issues. } \\
\text { Variable kinetics of distribution processes. } \\
\text { They are susceptible to physical instability. }\end{array}$ \\
\hline Dendrimers & $\begin{array}{l}\text { They increase stability of therapeutic agents. } \\
\text { They are easily prepared and functionalized. } \\
\text { They increase bioavailability of drugs. } \\
\text { They covalently associate drugs. } \\
\text { Dendrimers also act like solubility enhancers, increasing } \\
\text { the permeation of lipophilic drugs. }\end{array}$ & $\begin{array}{l}\text { They have shown cellular toxicity. } \\
\text { Elimination and metabolism could be a problem } \\
\text { depending on the generation and materials. } \\
\text { Their synthesis costs are higher than other } \\
\text { nanocarriers. } \\
\text { Hemolytic effects can be found. } \\
\text { They are not good carriers for hydrophilic drugs. }\end{array}$ \\
\hline $\begin{array}{l}\text { Niosomes, } \\
\text { transfersomes, } \\
\text { ethosomes }\end{array}$ & $\begin{array}{l}\text { Biodegradable and low toxicity. } \\
\text { Easy to prepare. } \\
\text { Softness, malleability. } \\
\text { They can encapsulate both hydrophilic and lipophilic } \\
\text { moieties. } \\
\text { Ability to target organs for drug delivery. } \\
\text { Extremely high flexibility of their membrane. }\end{array}$ & $\begin{array}{l}\text { Predisposition to oxidative degradation. } \\
\text { Purity of natural phospholipids. } \\
\text { Formulations are expensive. }\end{array}$ \\
\hline
\end{tabular}

Moreover, the ethosomal system dramatically enhanced the skin permeation of minoxidil in vitro compared with either ethanolic or hydroethanolic solution or phospholipid ethanolic micellar solution of minoxidil. In addition, the transdermal delivery of testosterone from an ethosomal patch was greater both in vitro and in vivo than from commercially available patches. ${ }^{104}$

Dendrimers have been utilized for transdermal drug delivery, as shown in Table 3. The main problems with this kind of transdermal carrier are their poor biodegradation and inherent cytotoxicity. ${ }^{105}$ The main advantage of dendrimers is that they have multivalency, ${ }^{106}$ and it is possible to precisely control the functional groups on the surface. ${ }^{107}$ Due to their form and size, these molecules can carry drugs, imaging agents, etc. Dendrimers interact with lipids present in membranes, and they show better permeation in cell cultures and intestinal membranes. Dendrimers also act like solubility enhancers, increasing the permeation of lipophilic drugs. On the other hand, they are not good carriers for hydrophilic drugs and the mechanisms underlying permeation enhancement and the interaction of dendrimers with skin are shown in Table 4.

Niosomes are versatile carrier systems that can be administered through various routes, including transdermal delivery. ${ }^{108,109}$ Particular efforts have been aimed at using niosomes as effective dermal and transdermal drug-delivery systems. ${ }^{10,111}$ In particular, niosomes are considered an interesting drug-delivery system in the treatment of dermatological disorders.

Niosomes have been reported to enhance the residence time of drugs in the SC and epidermis, while reducing the systemic absorption of the drug, and improve penetration of the trapped substances across the skin. In addition, these systems have been reported to decrease side effects and to give a considerable drug release. ${ }^{112}$ Niosomes formed from sorbitan monoesters (Span) with cholesterol molar ratios of 1:1 are a promising approach for the topical delivery of minoxidil in hair-loss treatment. ${ }^{113}$ Junyaprasert et al demonstrated that the 
Table 4 Summary of the applications of nanocarriers in transdermal drug delivery

\begin{tabular}{|c|c|}
\hline Type of transdermal nanocarriers & Applications \\
\hline \multirow[t]{6}{*}{ Liposomes } & Liposomes can encapsulate both lipophilic and hydrophilic drugs in a stable manner. Moreover, many \\
\hline & liposome-based drugs have been approved for use in the clinic. \\
\hline & Currently, positively charged liposomes have been used for DNA delivery in gene therapy. Also, liposomes \\
\hline & are being used for many antifungal and anticancer applications. \\
\hline & Examples of drugs delivered throughout the skin by using liposomes are melatonin, ${ }^{116}$ indinavir, ${ }^{117}$ \\
\hline & methotrexate, ${ }^{126}$ amphotericin B, ${ }^{127}$ ketoprofen, ${ }^{128}$ estradiol, ${ }^{129}$ clindamicyn hydrochloride, and lignocaine. ${ }^{130}$ \\
\hline \multirow[t]{6}{*}{ Transfersomes } & Several studies have reported that deformable liposomes were able to improve in vitro skin delivery of \\
\hline & various drugs, ${ }^{131-133}$ and to penetrate intact skin in vivo, transferring therapeutic amounts of drugs, ${ }^{134-136}$ \\
\hline & with efficiency comparable to subcutaneous administration. ${ }^{137}$ \\
\hline & Examples of transdermal drug delivery using transformable liposomes (transfersomes) are diclofenac, \\
\hline & insulin, tetanus toxoid, corticosteroids, superoxide dismutase, DNA, triamcinolone-acetonide, ketoprofen, \\
\hline & interleukin-2, and ketotifen fumarate. \\
\hline \multirow[t]{4}{*}{ Ethosomes } & At this time, ethosomes could be used in the treatment of atopic dermatitis. ${ }^{100}$ Furthermore, ethosomes \\
\hline & can be used for Parkinsonian syndrome and for dystonia therapy. ${ }^{138}$ \\
\hline & Examples of transdermal drug delivery using ethosomes are tacrolimus, ${ }^{100}$ clotrimazole, ${ }^{139}$ trihexyphenidyl \\
\hline & $\mathrm{HCl},{ }^{140}$ ketoprofen, ${ }^{101}$ and testosterone. \\
\hline \multirow[t]{5}{*}{ Niosomes } & Niosomal formulations have greater potential for drug cutaneous targeting and could be used as a feasible \\
\hline & cargo carrier for the topical delivery of minoxidil in skin diseases such as hair loss. Moreover, topical \\
\hline & application of niosomes can increase the residence time of drugs in the stratum corneum and epidermis, \\
\hline & while reducing the systemic absorption of the drug. ${ }^{114}$ \\
\hline & Examples of transdermal drug delivery using niosomes are minoxidil and ellagic acid. \\
\hline \multirow[t]{9}{*}{ Dendrimers } & Dendrimers have been used in numerous applications such as gene therapy, ${ }^{141}$ delivery of contrast \\
\hline & agents, ${ }^{142}$ controlled drug delivery, ${ }^{138,144}$ light-harvesting agents, ${ }^{143,144}$ catalysts, ${ }^{145}$ chemical sensors, ${ }^{146}$ and \\
\hline & cross-linking agents. \\
\hline & Additionally, dendrimers can be used in antiviral and anticancer pharmaceutical therapies, including \\
\hline & vaccines. ${ }^{147,148}$ \\
\hline & Dendrimers also act like solubility enhancers, increasing the permeation of lipophilic drugs. \\
\hline & Finally, dendrimers have been studied to assess biocompatibility and toxicity. ${ }^{149}$ \\
\hline & Examples of drugs delivered throughout the skin by using dendrimers are tamsulosin, ${ }^{150}$ indomethacin, ${ }^{151}$ \\
\hline & ketoprofen, diflunisal, ${ }^{152} 5$-fluorouracil, ${ }^{153}$ and peptides. ${ }^{154}$ \\
\hline \multirow[t]{7}{*}{ Nanoparticles } & Nanoparticles have been used successfully in the treatment of diseases such as cancer and diabetes. ${ }^{155}$ \\
\hline & Furthermore, polymeric nanoparticles are used to deliver therapeutic agents for various types of tumors, \\
\hline & bone healing, and vaccination. \\
\hline & Examples of drugs delivered throughout the skin by using nanoparticles are minoxidil, ${ }^{156}$ triptolide, ${ }^{157}$ \\
\hline & DNA, ${ }^{158}$ triamcinolone acetonide acetate, ${ }^{159}$ dexamethasone phosphate, ${ }^{160}$ cyclosporin $A,{ }^{161}$ flufenamic \\
\hline & acid, ${ }^{162}$ testosterone, ${ }^{162}$ caffeine, ${ }^{162} 5$-fluorouracil, ${ }^{163}$ arthemeter, ${ }^{164}$ chlorhexidine, ${ }^{165}$ econazole nitrate, ${ }^{166}$ \\
\hline & insulin, ${ }^{167}$ celecoxib, ${ }^{168}$ coenzyme $Q_{10}{ }^{169}$ and triclosan. ${ }^{170}$ \\
\hline
\end{tabular}

Span 60 and Tween 60 niosomes may be a potential carrier for dermal delivery of ellagic acid. ${ }^{114}$

Nanoparticles have been successful in the therapy and diagnosis of cancer; this disease causes many deaths in developed countries every year. ${ }^{115}$ While many cancer drugs destroy both cancer and healthy cells, nanoparticles represent a more targeted solution to drug delivery. Nanoparticles have also been used for vaccine development because they offer features not found in other carriers: they are chemically stable and reproducible. As peptide vectors, nanoparticles have shown much better performance than traditional adjuvants in vaccine development. ${ }^{116}$ Nanoparticles are important because many recently developed drugs are insoluble, and they offer a lot of types, eg, solid lipid nanoparticles and nanostructured lipid carriers. One of the most helpful recent developments involves $\mathrm{pH}$-sensitive nanoparticles. ${ }^{117}$ Moreover, polymeric nanoparticles are used to deliver therapeutic agents for various types of tumors, diabetes, bone healing, and vaccination (Table 4).

At present transdermal delivery using nanoemulsions is not used as much as nanoparticle or liposome delivery, due to the stability problems inherent to this dosage form. Nevertheless, gamma tocopherol, caffeine, plasmid DNA, aspirin, methyl salicylate, insulin, and nimesulide have been included in nanoemulsions. The use of these nanocarriers to deliver analgesics, corticosteroids, anticancer agents, etc, is very important, as these drugs are able to act immediately because they do not need to cross extra barriers..$^{93,118-123}$ 


\section{Conclusion}

The greatest challenge with transdermal drug delivery is the barrier nature of skin, which restricts the entry of most of the drugs. Currently, nanocarriers have been tried and tested to overcome the barrier of SC to achieve higher transdermal permeability, and they have been designed to avoid immune system rejection and to reach target sites. Moreover, the routes these nanocarriers follow are very different. The main advantages of using nanocarriers arise from their peculiar features, such as their tiny size, high surface energy, composition, architecture, and attached molecules. Thus, nanocarriers can penetrate biological membranes to deliver drugs for specific diseases. Advances with regard to materials, fabrication methods, and techniques facilitate the development of new and better nanocarriers. Nonetheless, future research must ensure the benefit and evaluate the risk ratio for many drugs included in nanocarriers.

\section{Acknowledgments}

Dr José Juan Escobar-Chávez wishes to acknowledge PAPIIT TA200-312, Cátedra PACIVE NCONS-17 and PAPIME 203612.

\section{Disclosure}

The authors report no conflicts of interest.

\section{References}

1. Brower V. Is nanotechnology ready for primetime? J Natl Cancer Inst. 2006;98:9-11.

2. Escobar-Chávez JJ, Rodriguez Cruz IM, Dominguez-Delgado CL, Díaz-Torres R, Revilla-Vázquez AL, Casas-Aléncaster N. Nanocarrier systems for transdermal drug delivery. In: Ali Demir Sezer, editor. Recent Advances in Novel Drug Carrier Systems. Rijeka: InTech; In press 2012.

3. Escobar-Chávez JJ, Rodriguez Cruz IM, Dominguez-Delgado CL. Chemical and physical enhancers for transdermal drug delivery. In: Gallelli L, editor. Pharmacology. Rijeka: InTech; 2012:397-433.

4. Díaz-Torres R. Transdermal nanocarriers. In: Escobar-Chávez JJ, Merino V, editors. Current Technologies to Increase the Transdermal Delivery of Drugs. Bussum: Bentham Science; 2010:120-140.

5. Hadgraft J, Lane ME. Skin permeation: the years of enlightenment. Int J Pharm. 2005;305:2-12.

6. Barry BW. Novel mechanisms and devices to enable successful transdermal drug delivery. Eur J Pharm Sci. 2001;14:101-104.

7. Rizwan M, Aqil M, Talegaonkar S, Azeem A, Sultana Y, Ali A. Enhanced transdermal drug delivery techniques: an extensive review of patents. Recent Pat Drug Deliv Formul. 2009;3:105-124.

8. Escobar-Chávez JJ, Merino V, editors. Current Technologies to Increase the Transdermal Delivery of Drugs. Bussum: Bentham Science; 2010.

9. Escobar-Chávez JJ, Bonilla-Martínez D, Villegas-González A, RodríguezCruz IM, Domínguez-Delgado CL. The use of sonophoresis in the administration of drugs through the skin. J Pharm Pharmaceut Sci. 2009;12:88-115.
10. Escobar-Chávez JJ, Merino V, López-Cervantes M, Rodríguez-Cruz IM, Quintanar-Guerrero D, Ganem-Quintanar A. The use of iontophoresis in the administration of nicotine and new non-nicotine drugs through the skin for smoking cessation. Curr Drug Discov Technol. 2009; 6:171-185.

11. Escobar-Chávez JJ, Bonilla-Martínez D, Villegas-González A, Revilla-Vazquez AL. Electroporation as an efficient physical enhancer for transdermal drug delivery. J Clin Pharmacol. 2009;49: 1262-1283.

12. Papakostas D, Rancan F, Sterry W, Blume-Peytavi U, Vogt A. Nanoparticles in dermatology. Arch Dermatol Res. 2011;303: 533-550.

13. Kristl J, Teskac K, Grabnar PA. Current view on nanosized solid lipid carriers for drug delivery to the skin. J Biomed Nanotechnol. 2010;6:529-542.

14. Schroeter A, Engelbrecht T, Neubert RH, Goebel AS. New nanosized technologies for dermal and transdermal drug delivery: a review. J Biomed Nanotechnol. 2010;6:511-528.

15. Neubert RH. Potentials of new nanocarriers for dermal and transdermal drug delivery. Eur J Pharm Biopharm. 2011;77:1-2.

16. Desai P, Patlolla RR, Singh M. Interaction of nanoparticles and cellpenetrating peptides with skin for transdermal drug delivery. $\mathrm{Mol}$ Membr Biol. 2010;27:247-259.

17. Chourasia R, Jain SK. Drug targeting through pilosebaceous route. Curr Drug Targets. 2009;10:950-967.

18. Gasco MR, Gasco P. Nanovector. Nanomedicine (Lond). 2007;2: 955-960.

19. Magdassi S. Delivery systems in cosmetics. Colloids Surf A Physicochem Eng Asp. 1997;123-124:671-679.

20. Luppi B, Cerchiara T, Bigucci F, Basile R, Zecchi V. Polymeric nanoparticles composed of fatty acids and polyvinylalcohol for topical application of sunscreens. J Pharm Pharmacol. 2004;56:407-411.

21. Kaur IP, Agrawal R. Nanotechnology: a new paradigm in cosmeceuticals. Recent Pat Drug Deliv Formul. 2007;1:171-182.

22. Alvarez-Roman R, Barre G, Guy RH, Fessi H. Biodegradable polymer nanocapsules containing a sunscreen agent: preparation and photoprotection. Eur J Pharm Biopharm. 2001;52:191-195.

23. Escobar Chávez JJ, Merino-Sanjuan V, López-Cervantes M, et al. The tape-stripping technique as a method for drug quantification in skin. J Pharm Pharmaceut Sci. 2008;11:104-130.

24. Potts RO, Francoeur ML. The influence of stratum corneum morphology on water permeability. J Invest Dermatol. 1991;96:495-499.

25. Potts RO, Guy RH. Predicting skin permeability. Pharm Res. 1992;9:663-669

26. Ellias PM. Epidermal barrier function: intercellular lamellar lipid structures, origin, composition and metabolism. J Control Release. 1991;15:199-208.

27. Escobar-Chávez JJ, Melgoza-Contreras LM, López-Cervantes M, et al. The tape-stripping technique as a valuable tool for evaluating topical applied compounds. In: Gary W, Caldwell GW, Atta-ur-Rahman, Yan Z, Choudhary MI, editors. Frontiers in Drug Design and Discovery. Bussum: Bentham Science; 2009;4:189-227.

28. Hadgraft J. Skin, the final frontier. Int J Pharm. 2001;224:1-18

29. Guy RH, Hadgraft J. Transdermal Drug Delivery. 2nd ed. New York: Marcel Dekker; 2002.

30. Nevill AM. The need to scale for differences in body size and mass: and explanation of Klieber's 0.75 mass exponent. J Appl Physiol. 1994;77:2870-2873.

31. Domínguez-Delgado CL, Rodríguez-Cruz IM, López-Cervantes M. The skin: a valuable route for administration of drugs. In: Escobar-Chávez JJ, Virginia Merino M, editors. Current Technologies to Increase the Transdermal Delivery of Drugs. Bussum: Bentham Science; 2010:1-22.

32. Escobar-Chávez JJ, Merino V, Díez-Sales O, et al. Transdermal nortriptyline hydrochloride patch formulated within a chitosan matrix intended to be used for smoking cessation. Pharm Dev Technol. 2011;16:162-169. 
33. Escobar-Chávez JJ, López-Cervantes M, Naïk A, Kalia YN, QuintanarGuerrero D, Ganem Quintanar A. Applications of the thermoreversible Pluronic F-127 gels in pharmaceutical formulations. J Pharm Pharmaceut Sci. 2006;9:339-358.

34. Domínguez-Delgado CL, Rodríguez-Cruz IM, Escobar-Chávez JJ, Calderón-Lojero IO, Quintanar-Guerrero D, Ganem A. Preparation and characterization of triclosan nanoparticles intended to be used for the treatment of acne. Eur J Pharm Biopharm. 2011,79:102-107.

35. Fang JY, Leu YL, Wang YY, Tsai YH. In vitro topical application and in vivo pharmacodynamic evaluation of nonivamide hydrogels using Wistar rat as an animal model. Eur J Pharm Sci. 2002;15:417-423.

36. Shin SC, Cho CW, Oh IJ. Effects of non ionic surfactants as permeation enhancers towards piroxicam from the poloxamer gel through rat skins. Int J Pharm. 2001;222:199-203.

37. Liaw J, Lin Y. Evaluation of poly(ethylene oxide)-poly(propylene oxide)-poly(ethylene oxide) (PEO-PPO-PEO) gels as a release vehicle for percutaneous fentanyl. J Control Release. 2000;68:273-282.

38. Wang YY, Hong CT, Chiu WT, Fang JY. In vitro and in vivo evaluations of topically applied capsaicin and nonivamide from hydrogels. Int J Pharm. 2000;224:1-2.

39. Mattorano DA, Kupper LL, Nylander-French LA. Estimating dermal exposure to jet fuel (naphthalene) using adhesive tape strip samples. Ann Occup Hyg. 2004;48:139-146.

40. Chao YC, Nylander-French LA. Determination of keratin protein in a tape-stripped skin sample from jet fuel exposed skin. Ann Occup Hyg. 2004;48:65-73.

41. Illel B. Formulation for transfollicular drug administration: some recent advances. Crit Rev Ther Drug Carrier Syst. 1997;14:207-219.

42. Xiang TX, Anderson BD. Influence of chain ordering on the selectivity of dipalmitoylphosphatidylcholine bilayer membranes for permeant size and shape. Biophys J. 1998;75:2658-2671.

43. Geinoz S, Guy RH, Testa B, Carrupt PA. Quantitative structurepermeation relationships (QSPeRs) to predict skin permeation: a critical evaluation. Pharm Res. 2004;21:83-92.

44. Cevc G. Drug delivery across the skin. Expert Opin Investig Drugs. 1997;6:1887-1937.

45. Potts RO, Guy RH. Predicting skin permeability. Pharm Res. 1992;9: 663-669.

46. Cevc G, Vierl U. Nanotechnology and the transdermal route. A state of the art review and critical appraisal. J Control Release. 2010;141: 277-299.

47. Schätzlein A, Cevc G. Non-uniform cellular packing of the stratum corneum and permeability barrier function of intact skin: a high-resolution confocal laser scanning microscopy study using highly deformable vesicles (Transfersomes). Br J Dermatol. 1998;138:583-592.

48. Mitragotri S. Modeling skin permeability to hydrophilic and hydrophobic solutes based on four permeation pathways. J Control Release. 2003;86:69-92.

49. Aguilella V, Kontturi K, Murtomiiki L, Ramírez P. Estimation of the pore size and charge density in human cadaver skin. $J$ Control Release. $1994 ; 32: 249-257$.

50. Johnson ME, Blankschtein D, Langer R. Evaluation of solute permeation through the stratum corneum: lateral bilayer diffusion as the primary transport mechanism. J Pharm Sci. 1997;86:1162-1172.

51. Russell LM, Guy RH. Novel imaging method to quantify stratum corneum in dermatopharmacokinetic studies. Pharm Res. 2012;29(9): 2389-2397.

52. Xiang TX, Anderson BD. Influence of chain ordering on the selectivity of dipalmitoylphosphatidylcholine bilayer membranes for permeant size and shape. Biophys J. 1998;75:2658-2671.

53. Meidan VM, Docker M, Walmsley AD, Irwin WJ. Low intensity ultrasound as a probe to elucidate the relative follicular contribution to total transdermal absorption. Pharm Res. 1998;15:85-92.

54. Ogiso T, Shiraki T, Okajima K, Tanino T, Iwaki M, Wada T. Transfollicular drug delivery: penetration of drugs through human scalp skin and comparison of penetration between scalp and abdominal skins in vitro. J Drug Target. 2002;10:369-378.
55. Dokka S, Cooper SR, Kelly S, Hardee GE, Karras JG. Dermal delivery of topically applied oligonucleotides via follicular transport in mouse skin. J Invest Dermatol. 2005;124:971-975.

56. Grams YY, Whitehead L, Lamers G, Sturman N, Bouwstra JA. Online diffusion profile of a lipophilic dye in different depths of a hair follicle in human scalp skin. $J$ Invest Dermatol. 2005;125: 775-782.

57. Jacobi U, Toll R, Sterry W, Lademann J. Do follicles play a role as penetration pathways in in vitro studies on porcine skin? An optical study. Laser Phys. 2005;15:1594-1598.

58. Teichmann A, Ossadnik M, Richter H, Sterry W, Lademann J. Semiquantitative determination of the penetration of a fluorescent hydrogel formulation into the hair follicle with and without follicular closure by microparticles by means of differential stripping. Skin Pharmacol Physiol. 2006;19:101-105.

59. Alvarez-Román R, Naik A, Kalia YN, Guy RH, Fessi H. Skin penetration and distribution of polymeric nanoparticles. $J$ Control Release. 2004;99:53-62.

60. Essa EA, Bonner MC, Barry BW. Human skin sandwich for assessing shunt route penetration during passive and iontophoretic drug and liposome delivery. J Pharm Pharmacol. 2002;54:1481-1490.

61. Escobar-Chávez JJ, López-Cervantes M, Ganem Rondero A. Conventional methods for cutaneous drug sampling. In: Narasimha Murthy S, editor. Dermatokinetics of Therapeutic Agents. Boca Raton: CRC Press; 2011:81-130.

62. Teichmann A, Jacobi U, Ossadnik M, et al. Differential stripping: determination of the amount of topically applied substances penetrated into the hair follicles. J Invest Dermatol. 2005;125:264-269.

63. Prochazka AV. New developments in smoking cessation. Chest. 2000;117:169S-175S

64. Wilkosz MF, Bogner RH. Transdermal drug delivery. Part 1: Current status. US Pharm. 2003;28.

65. Mishra V, Bhargava S. Transdermal drug delivery system - a total view. Available from: http://www.pharmatutor.org/articles/transdermal-drugdelivery-system-a-total-view. Accessed July 5, 2012.

66. Cho K, Wang X, Nie S, Shin DM. Therapeutic nanoparticles for drug delivery in cancer. Clin Cancer Res. 2008;14:1310-1316.

67. Blynskaya E, Alekseev K, Alyautdin R. Perspectives of the development of pharmaceutical nanotechnology. Russ J Gen Chem. 2012;82: 519-526.

68. Panariti A, Miserocchi G, Rivolta I. The effect of nanoparticle uptake on cellular behavior: disrupting or enabling functions? Nanotechnol Sci Appl. 2012;2012:87-100.

69. Andrade F, Videira M, Ferreira D, Sarmento B. Nanocarriers for pulmonary administration of peptides and therapeutic proteins. Nanomedicine (Lond). 2011;6:123-141.

70. Marchetti JM, de Souza MC, Marotta-Oliveira SS. Nanocarriers and cancer therapy: approaches to topical and transdermal delivery. In: Beck R, Guterres S, Pohlmann A, editors. Nanocosmetics and Nanomedicines: New Approaches for Skin Care. Heidelberg: Springer; 2011:269.

71. Pailler-Mattei C, Bec S, Zahouani H. In vivo measurements of the elastic mechanical properties of human skin by indentation tests. Med Eng Phys. 2008;30:599-606.

72. Grice JE, Ciotti S, Weiner N, Lockwood P, Cross SE, Roberts MS. Relative uptake of minoxidil into appendages and stratum corneum and permeation through human skin in vitro. J Pharm Sci. 2010;99:712-718.

73. Bakowsky H, Richter T, Kneuer C, et al. Adhesion characteristics and stability assessment of lectin-modified liposomes for site-specific drug delivery. Biochim Biophys Acta. 2008;1778:242-249.

74. Zaborova O, Sybachin A, Ballauff M, Yaroslavov A. Structure and properties of complexes of polycationic brushes with anionic liposomes. Polym Sci Ser A Chem Phys. 2011;53:1019-1025.

75. Touitou E, Junginger H, Weiner N, Nagai T, Mezei M. Liposomes as carriers for topical and transdermal delivery. J Pharm Sci. 1994;83:1189-1203. 
76. Gandhi AA, Chaskar S, Jadhav SP, Salunkhe KS. Transfersomes. In: International Medical Commission of Bhopal, editor. Transdermal Drug Delivery. Bhopal: Inventi Impact; 2011.

77. Patel R, Singh S, Singh S, Sheth N, Gendle R. Development and characterization of curcumin loaded transfersome for transdermal delivery. J Pharm Sci Res. 2009;1:71-80.

78. Madsen JT, Vogel S, Karlberg AT, Simonsson C, Johansen JD, Andersen KE. Ethosome formulations of known contact allergens can increase their sensitizing capacity. Acta Derm Venereol. 2010;90(4):374-378.

79. Chourasia MK, Kang L, Yung Chan S. Nanosized ethosomes bearing ketoprofen for improved transdermal delivery. Results Pharma Sci. 2011;1:60-67.

80. Pannala S, Sri Samala U. Ethosomes, a novel transdermal drug delivery systems: a review. J Pharm Res. 2012;4:4628-4630.

81. Keservani RK, Sharma AK, Ramteke S. Novel vesicular approach for topical delivery of baclofen via niosomes. Lat Am J Pharm. 2010;29:1364-1370.

82. Kumar GP, Rao PR. Ultra deformable niosomes for improved transdermal drug delivery: the future scenario. Asian J Pharm Sci. 2012;7:96-109.

83. Astruc D, Boisselier E, Ornelas C. Dendrimers designed for functions: from physical, photophysical, and supramolecular properties to applications in sensing, catalysis, molecular electronics, photonics, and nanomedicine. Chem Rev. 2010;110:1857-1959.

84. Uchegbu I, Dufès CM, Kan PL, Schätzlein A. Polymers and dendrimers for gene delivery in gene therapy. In: Templeton NS, editor. Gene and Cell Therapy: Therapeutic Mechanisms and Strategies, 3rd ed. Boca Raton: CRC Press; 2008.

85. Svenson S. Dendrimers as versatile platform in drug delivery applications. Eur J Pharm Biopharm. 2009;71:445-462.

86. James-Smith MA, Hellner B, Annunziato N, Mitragotri S. Effect of surfactant mixtures on skin structure and barrier properties. Ann Biomed Eng. 2011;39:1215-1223.

87. Huang Y, Yu F, Park YS, et al. Co-administration of protein drugs with gold nanoparticles to enable percutaneous delivery. Biomaterials. 2010;31:9086-9091

88. Labouta H, Kraus T, El-Khordagui LK, Schneider M. Combined multiphoton imaging-pixel analysis for semiquantitation of skin penetration of gold nanoparticles. Int J Pharmaceutics. 2011;413:279-282.

89. Mihranyan A, Ferraz N, Strømme M. Current status and future prospects of nanotechnology in cosmetics. Prog Mater Sci. 2012;57: 875-910.

90. Prow TW, Grice JE, Lin LL, et al. Nanoparticles and microparticles for skin drug delivery. Adv Drug Deliv Rev. 2011;63:470-491.

91. Mohanraj V, Chen Y. Nanoparticles - a review. Trop J Pharm Res. 2007;5:561-573.

92. Cappel MJ, Kreuter J. Effect of nanoparticles on transdermal drug delivery. J Microencapsul. 1991;8:369-374.

93. Yin YS, Chen DW, Qiao MX, Lu Z, Hu HY. Preparation and evaluation of lectin-conjugated PLGA nanoparticles for oral delivery of thymopentin. J Control Release. 2006;116:337-345.

94. Shakeel F, Ramadan W. Transdermal delivery of anticancer drug caffeine from water-in-oil nanoemulsions. Colloids Surf B Biointerfaces. 2010;75:356-362.

95. Sonneville-Aubrun O, Simonnet JT, L'Alloret F. Nanoemulsions: a new vehicle for skincare products. Adv Colloid Interface Sci. 2004;108-109:145-149.

96. Symon Z, Peyser A, Tzemach D, et al. Selective delivery of doxorubicin to patients with breast carcinoma metastases by stealth liposomes. Cancer. 1999;86:72-78.

97. Gonçalves A, Braud AC, Viret F, et al. Phase I study of pegylated liposomal doxorubicin (Caelyx) in combination with carboplatin in patients with advanced solid tumors. Anticancer Res. 2003;23:3543-3548.

98. Seiden MV, Muggia F, Astrow A, et al. A phase II study of liposomal lurtotecan (OSI-211) in patients with topotecan resistant ovarian cancer. Gynecol Oncol. 2004;93:229-232.
99. El Maghraby GMM, Williams AC, Barry BW. Can drugbearing liposomes penetrate intact skin? J Pharm Pharmacol. 2006;58:415-429.

100. Li G, Fan Y, Fan C, et al. Tacrolimus-loaded ethosomes: physicochemical characterization and in vivo evaluation. Eur J Pharm Biopharm. In press 2012.

101. Chourasia MK, Kang L, Chan SY. Nanosized ethosomes bearing ketoprofen for improved transdermal delivery. Results Pharm Sci. 2011;1:60-67.

102. Fang YP, Huang YB, Wua PC, Tsai YH. Topical delivery of 5-aminolevulinic acid-encapsulated ethosomes in a hyperproliferative skin animal model using the CLSM technique to evaluate the penetration behavior. Eur J Pharm Biopharm. 2009;73:391-398.

103. Paolino D, Lucania G, Mardente D, Alhaique F, Fresta M. Ethosomes for skin delivery of ammonium glycyrrhizinate: in vitro percutaneous permeation through human skin and in vivo anti-inflammatory activity on human volunteers. J Control Release. 2005;106:99-110.

104. Touitou E, Dayan N, Bergelson L, Godina B, Eliaz M. Ethosomes novel vesicular carriers for enhanced delivery: characterization and skin penetration properties. J Control Release. 2000;65:403-418.

105. Parekh HS. The advance of dendrimers - a versatile targeting platform for gene/drug delivery. Curr Pharm Des. 2007;13:2837-2850.

106. Esfand R, Tomalia DA. Poly(amidoamine) (PAMAM) dendrimer: from biomimicry to drug delivery and biomedical applications. Drug Discov Today. 2001;6:427-436.

107. D'Emanuele A, Attwood D. Dendrimer-drug interactions. Adv Drug Deliv Rev. 2005;57:2147-2162.

108. Alsarra IA, Bosela AA, Ahmed SM, Mahrous GM. Proniosomes as a drug carrier for transdermal delivery of ketorolac. Eur J Pharm Biopharm. 2005;59:485-490.

109. Muzzalupo R, Tavano L, Cassano R, Trombino S, Ferrarelli T, Picci N. A new approach for the evaluation of niosomes as effective transdermal drug delivery systems. Eur J Pharm Biopharm. 2011;79:28-35.

110. Manconi M, Caddeo C, Sinico C, et al. Ex vivo skin delivery of diclofenac by transcutol containing liposomes and suggested mechanism of vesicle-skin interaction. Eur J Pharm Biopharm. 2011;78:27-35

111. Mura S, Manconi M, Sinico C, Valenti D, Fadda AM. Penetration enhancer containing vesicles (PEVs) as carriers for cutaneous delivery of minoxidil. Int J Pharm. 2009;380:72-79.

112. Guinedi AS, Mortada ND, Mansour S, Hathout RM. Preparation and evaluation of reverse-phase evaporation and multilamellar niosomes as ophthalmic carriers of acetazolamide. Int J Pharm. 2005;306:71-82.

113. Balakrishnana P, Shanmugama S, Lee WS, et al. Formulation and in vitro assessment of minoxidil niosomes for enhanced skin delivery. Int J Pharm. 2009;377:1-8.

114. Junyaprasert VB, Singhsa P, Suksiriworapong J, Chantasart D. Physicochemical properties and skin permeation of Span 60/Tween 60 niosomes of ellagic acid. Int J Pharm. 2012;423:303-311.

115. World Health Organization. The International Agency for Research on Cancer (IARC). Available from: http://www.iarc.fr. Accessed January 15, 2010.

116. Cui Z, Han S, Padinjarae D, Huang L. Immunostimulation mechanism of LPD nanoparticles as a vaccine carrier. Mol Pharm. 2005;2:22-28.

117. Herffernan M, Murthy N. Polyketal nanoparticles: a new pHsensitive biodegradable drug delivery vehicle. Bioconjug Chem. 2005;16:1340-1342.

118. Kuo F, Subramanian B, Kotyla T, Wilson TA, Yoganathan S, Nicolosi RJ. Nanoemulsions of an anti-oxidant synergy formulation containing gamma tocopherol have enhanced bioavailability and antiinflammatory properties. Int J Pharm. 2008;363:206-213.

119. Wu H, Ramachandran C, Bielinska AU, et al. Topical transfection using plasmid DNA in a water-in-oil nanoemulsion. Int J Pharm. 2001;221:23-34. 
120. Subramanian B, Kuo F, Ada E, et al. Enhancement of anti-inflammatory property of aspirin in mice by a nano-emulsion preparation. Int Immunopharmacol. 2008;8:1533-1539.

121. Mou D, Chen H, Du D, et al. Hydrogel-thickened nanoemulsion system for topical delivery of lipophilic drugs. Int J Pharm. 2008;353:270-276.

122. Wu H, Ramachandran C, Weiner ND, Roessler BJ. Topical transport of hydrophilic compounds using water-in-oil nanoemulsions. Int $J$ Pharm. 2001;220:63-75.

123. Alves MP, Scarrone AL, Santos M, Pohlmann AR, Guterres SS. Human skin penetration and distribution of nimesulide from hydrophilic gels containing nanocarriers. Int J Pharm. 2007;341:215-220.

124. Dubey V, Mishra D, Jain NK. Melatonin loaded ethanolic liposomes: physicochemical characterization and enhanced transdermal delivery. Eur J Pharm Biopharm. 2007;67:398-405.

125. Dubey V, Mishra D, Nahar M, Jain V, Jain NK. Enhanced transdermal delivery of an anti-HIV agent via ethanolic liposomes. Nanomedicine. 2010;6:590-596.

126. Dubey V, Mishra D, Dutta T, Nahar M, Saraf DK, Jain NK. Dermal and transdermal delivery of an anti-psoriatic agent via ethanolic liposomes. J Control Release. 2007;123:148-154.

127. Manosroi A, Kongkaneramit L, Manosroi J. Stability and transdermal absorption of topical amphotericin B liposome formulations. Int $J$ Pharm. 2004;270:279-286.

128. Maestrelli F, González-Rodríguez ML, Rabasco AM, Mura P. Preparation and characterisation of liposomes encapsulating ketoprofen-cyclodextrin complexes for transdermal drug delivery. Int $J$ Pharm. 2005;298:55-67.

129. Essa EA, Bonner MC, Barry BW. Electrically assisted skin delivery of liposomal estradiol; phospholipid as damage retardant. J Control Release. 2004;95:535-546.

130. Sharma BB, Jain SK, Vyas SP. Topical liposome system bearing local anaesthetic lignocaine: preparation and evaluation. J Microencapsul. 1994;11:279-286.

131. Trotta M, Peira E, Debernardi F, Gallarate M. Elastic liposomes for skin delivery of dipotassium glycyrrhizinate. Int J Pharm. 2002;241:319-327.

132. Trotta M, Peira E, Carlotti ME, Gallarate M. Deformable liposomes for dermal administration of methotrexate. Int J Pharm. 2004;270:119-125.

133. Boinpally RR, Zhou SL, Poondru S, Devraj G, Jasti BR. Lecithin vesicles for topical delivery of diclofenac. Eur J Pharm Biopharm. 2003;56:389-392.

134. Cevc G, Blume G. New, highly efficient formulation of diclofenac for the topical, transdermal administration in ultradeformable drug carriers, transfersomes. Biochim Biophys Acta. 2001;1514: 191-205.

135. Ceve G, Blume G. Biological activity and characteristics of triamcinolone-acetonide formulated with the self-regulating drug carriers, transfersomes. Biochim Biophys Acta. 2003;1614:156-164.

136. Cevc G, Blume G. Hydrocortisone and dexamethasone in very deformable drug carriers have increased biological potency, prolonged effect, and reduced therapeutic dosage. Biochim Biophys Acta. 2004;1663:61-73.

137. Cevc G, Schatzlein AG, Richardsen H, Vierl U. Overcoming semipermeable barriers, such as the skin, with ultradeformable mixed lipid vesicles, Transfersomes, liposomes, or mixed lipid micelles. Langmuir. 2003;19:10753-10763.

138. Umesh Gupta U, Agashe HB, Asthana A, Jain NK. A review of in vitro-in vivo investigations on dendrimers: the novel nanoscopic drug carriers. Nanomedicine. 2006;2:66-73.

139. Maheshwari RGS, Tekade RK, Sharma PA, et al. Ethosomes and ultradeformable liposomes for transdermal delivery of clotrimazole: a comparative assessment. Saudi Pharm J. 2012;20:161-170.

140. Dayan N, Touitou E. Carriers for skin delivery of trihexyphenidyl HCl: ethosomes vs liposomes. Biomaterials. 2000;21:1879-1885.
141. Huang RQ, Qu YH, Ke WL, Zhu JH, Pei YY, Jiang C. Efficient gene delivery targeted to the brain using a transferring-conjugated polyethyleneglycol-modified polyamidoamine dendrimer. FASEB J. 2007;21:1117-1125.

142. Koyama Y, Talanov VS, Bernardo M, et al. A dendrimer-based nanosized contrast agent dual-labeled for magnetic resonance and optical fluorescence imaging to localize the sentinel lymph node in mice. J Magn Reson Imag. 2007;25:866-871.

143. Ahn TS, Thompson AL, Bharathi P, Müller A, Bardeen CJ. Lightharvesting in carbonyl-terminated phenylacetylene dendrimers: the role of delocalized excited states and the scaling of light-harvesting efficiency with dendrimer size. J Phys Chem B. 2006;110:19810-19819.

144. Wang JL, Luo J, Liu LH, Zhou LH, Ma Y, Pei J. Nanosized gradient pi-conjugated thienylethynylene dendrimers for light harvesting: synthesis and properties. Org Lett. 2006;8:2281-2284.

145. Wu L, Li BL, Huang YY, Zhou HF, He YM, Fan QH. Phosphine dendrimer-stabilized palladium nanoparticles: a highly active and recyclable catalyst for the Suzuki-Miyaura reaction and hydrogenation. Org Lett. 2006;8:3605-3608.

146. Svobodováa L, Šnejdárkováa M, Tóthb K, Gyurcsanyib RE, Hianik T. Properties of mixed alkanethiol-dendrimer layers and their applications in biosensing. Bioelectrochem. 2004;63:285-289.

147. Tomalia DA, Baker H, Dewald J, et al. A new class of polymers: starburst-dendritic macromolecules. Polym J. 1985;17:117-132.

148. Gillies ER, Fréchet JMJ. Dendrimers and dendritic polymers in drug delivery. Drug Discov Today. 2005;10:35-43.

149. Duncan R, Izzo L. Dendrimer biocompatibility and toxicity. Adv Drug Deliv Rev. 2005;57:2215-2237.

150. Wang Z, Itoh Z, Hosaka Y, et al. Novel transdermal drug delivery system with polyhydroxyalkanoate and starburst polyamidoamine dendrimer. J Biosci Bioeng. 2003;95:541-543.

151. Chauhan AS, Sridevi S, Chalasani KB, et al. Dendrimer-mediated transdermal delivery: enhanced bioavailability of indomethacin. J Control Release. 2003;90:335-343.

152. Yiyun $\mathrm{C}, \mathrm{Na} \mathrm{M}$, Tongwen $\mathrm{X}$, et al. Transdermal delivery of nonsteroidal anti-inflammatory drugs mediated by polyamidoamine (PAMAM) dendrimer. J Pharm Sci. 2007;96:595-602.

153. Venuganti VVK, Perumal OP. Effect of poly(amidoamine) (PAMAM) dendrimer on skin permeation of 5-fluorouracil. Int J Pharm. 2008;361:230-238.

154. Niederhafner P, Šebestík J, Ježek J. Peptide dendrimers. J Peptide Sci. 2005;11:757-788.

155. International Diabetes Federation. Diabetes action now. Available from: http://www.who.int/diabetes/actionnow/en/diabprev.pdf. Accessed January 20, 2010.

156. Shim J, Seok Kang H, Park W, Han S, Kim J, Chang I. Transdermal delivery of mixnoxidil with block copolymer nanoparticles. J Control Release. 2004;97:477-484.

157. Mei Z, Chen H, Weng T, Yang Y, Yang X. Solid lipid nanoparticle and microemulsion for topical delivery of triptolide. Eur J Pharm Biopharm. 2003;56:189-196.

158. Lee P, Peng S, Su C, et al. The use of biodegradable polymeric nanoparticles in combination with a low-pressure gene gun for transdermal DNA delivery. Biomaterials. 2008;29:742-751.

159. Liu W, Hu M, Liu W, Xue C, Xu H, Yang X. Investigation of the carbopol gel of solid lipid nanoparticles for the transdermal iontophoretic delivery of triamcinolone acetonide acetate. Int J Pharm. 2008;364:135-141.

160. Thote AJ, Gupta RB. Formation of nanoparticles of a hydrophilic drug using supercritical carbon dioxide and microencapsulation for sustained release. Nanomed Nanotechnol. 2005;1:85-90.

161. Ugazio E, Cavalli R, Gasco MR. Incorporation of cyclosporin A in solid lipid nanoparticles (SLN). Int J Pharm. 2002;241:341-344.

162. Santander-Ortega MJ, Stauner T, Loretz B, et al. Nanoparticles made from novel starch derivatives for transdermal drug delivery. J Control Release. 2010;141:85-92. 
163. McCarron PA, Hall M. Incorporation of novel 1-alkylcarbonyloxymethyl prodrugs of 5-fluorouracil into poly(lactide-coglycolide) nanoparticles. Int J Pharm. 2008;348:115-124.

164. Aditya NP, Patankar S, Madhusudhan B, Murthy RSR, Souto EB. Arthemeter-loaded lipid nanoparticles produced by modified thin-film hydration: pharmacokinetics, toxicological and in vivo anti-malarial activity. Eur J Pharm Sci. 2010;40:448-455.

165. Lboutounne H, Chaulet J, Ploton C, Falson F, Pirot F. Sustained ex vivo skin antiseptic activity of chlorhexidine in poly( $\varepsilon$-caprolactone) nanocapsule encapsulated form and as a digluconate. J Control Release. 2002;82:319-334.

166. Sanna V, Caria G, Mariani A. Effect of lipid nanoparticles containing fatty alcohols having different chain length on the ex vivo skin permeability of Econazole nitrate. Powder Technol. 2010;201:32-36
167. Huang X, Du Y, Yuan H, Hu F. Preparation and pharmacodynamics of low-molecular-weight chitosan nanoparticles containing insulin. Carbohydr Polym. 2009;76:368-373.

168. Joshi M, Patravale V. Nanostructured lipid carrier (NLC) based gel of celecoxib. Int J Pharm. 2008;346:124-132.

169. Teeranachaideekul V, Souto EB, Junyaprasert VB, Müller RH. Cetyl palmitate-based NLC for topical delivery of Coenzyme Q10 - development, physicochemical characterization and in vitro release studies. Eur J Pharm Sci. 2007;67:141-148.

170. Rodríguez-Cruz IM, Merino V, Merino M, Díez O, Nácher A, Quintanar-Guerrero D. Polymeric nanospheres as strategy to increase the amount of triclosan retained in the skin: passive diffusion vs iontophoresis. J Microencapsul. Epub July 3, 2012.

\section{Video abstract}

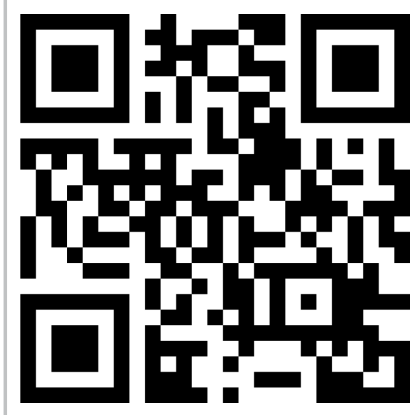

Point your SmartPhone at the code above. If you have a $Q R$ code reader the video abstract will appear. Or use: http://dvpr.es/TsSM55
Research and Reports in Transdermal Drug Delivery

\section{Publish your work in this journal}

Research and Reports in Transdermal Drug Delivery is an international, peer-reviewed, open access online journal publishing original research, study protocols, reviews, editorials and commentaries on all aspects of transdermal drug delivery. Specific topics in the journal include: Laboratory and clinical development of drug delivery systems including preclinical, clinical studies and protocols; Rationale and basic science; Drug

\section{Dovepress}

delivery via gels, creams or patches; Use of chemical drug penetration enhancers ; Patient acceptability studies; and pharmacoeconomic and clinical outcome studies. The manuscript management system is completely online and includes a very quick and fair peer-review system, which is all easy to use. Visit http://www.dovepress.com/ testimonials.php to read real quotes from published authors. 